University of Nebraska - Lincoln

DigitalCommons@University of Nebraska - Lincoln

\title{
Prevalence of West Nile Virus in Migratory Birds during Spring and
} Fall Migration

\author{
Robert J. Dusek \\ U.S. Geological Survey, National Wildlife Health Center, 6006 Schroeder Rd., Madison, WI, \\ rdusek@usgs.gov
}

Robert G. McLean

Laura D. Kramer

Sonya R. Ubico

Alan P. Dupuis II

See next page for additional authors

Follow this and additional works at: https://digitalcommons.unl.edu/usgsstaffpub

Part of the Earth Sciences Commons

Dusek, Robert J.; McLean, Robert G.; Kramer, Laura D.; Ubico, Sonya R.; Dupuis, Alan P. II; Ebel, Gregory D.; and Guptill, Stephen C., "Prevalence of West Nile Virus in Migratory Birds during Spring and Fall Migration" (2009). USGS Staff -- Published Research. 313.

https://digitalcommons.unl.edu/usgsstaffpub/313

This Article is brought to you for free and open access by the US Geological Survey at DigitalCommons@University of Nebraska - Lincoln. It has been accepted for inclusion in USGS Staff -- Published Research by an authorized administrator of DigitalCommons@University of Nebraska - Lincoln. 


\section{Authors}

Robert J. Dusek, Robert G. McLean, Laura D. Kramer, Sonya R. Ubico, Alan P. Dupuis II, Gregory D. Ebel, and Stephen C. Guptill 


\title{
Prevalence of West Nile Virus in Migratory Birds during Spring and Fall Migration
}

\author{
Robert J. Dusek,* Robert G. McLean, Laura D. Kramer, Sonya R. Ubico, \\ Alan P. Dupuis II, Gregory D. Ebel, and Stephen C. Guptill \\ United States Geological Survey, National Wildlife Health Center, Madison, Wisconsin; New York State Department of Health, \\ Slingerlands, New York; United States Geological Survey, Eastern Region Geography, Reston, Virginia
}

\begin{abstract}
To investigate the role of migratory birds in the dissemination of West Nile virus (WNV), we measured the prevalence of infectious WNV and specific WNV neutralizing antibodies in birds, principally Passeriformes, during spring and fall migrations in the Atlantic and Mississippi flyways from 2001-2003. Blood samples were obtained from 13,403 birds, representing 133 species. Specific WNV neutralizing antibody was detected in 254 resident and migratory birds, representing 39 species, and was most commonly detected in northern cardinals (Cardinalis cardinalis) $(9.8 \%, N=762)$ and gray catbirds (Dumetella carolinensis) $(3.2 \%, N=3188)$. West Nile virus viremias were detected in 19 birds, including 8 gray catbirds, and only during the fall migratory period. These results provide additional evidence that migratory birds may have been a principal agent for the spread of WNV in North America and provide data on the occurrence of WNV in a variety of bird species.
\end{abstract}

\section{INTRODUCTION}

West Nile virus (WNV) was first detected in North America in the fall of 1999 when dead birds began appearing in New York City and Long Island, New York. ${ }^{1}$ Since its initial detection, WNV has spread rapidly throughout North America. After the winter of 1999-2000, WNV reemerged in New York and New Jersey in the spring of 2000 and began spreading northward through the Northeast United States. ${ }^{2}$ In early 2001, it was detected again in the Northeast United States and in Florida and rapidly spread to the northern Midwestern states in early summer followed by a southward spread along the Mississippi River during the late summer and early fall.,4 By the end of 2002, every state east of the Rocky Mountains had reported WNV activity. ${ }^{5}$ In 2003, WNV activity in mosquitoes and sentinel and wild birds was first reported in California and major outbreaks in humans, equines, and birds occurred in Colorado and the northern Midwestern states. ${ }^{6,7}$ During this time WNV had also spread through much of eastern and central Canada, and into Mexico and the Caribbean. ${ }^{8-10}$

West Nile virus is a flavivirus closely related to St. Louis encephalitis virus (SLEV), and is maintained in the environment principally through a mosquito-bird-mosquito transmission cycle. ${ }^{11,12}$ The strain of WNV that was introduced to North America is highly virulent and is likely the primary cause of mortality for tens of thousands of North American birds. ${ }^{13}$ This strain of the virus also has caused serious and fatal disease in both humans and domestic animals. ${ }^{1}$

Different hypotheses have been put forward to explain this rapid expansion of WNV throughout North America. Migratory birds are thought to play a critical role in the movement of WNV. ${ }^{12,14-16}$ Little empirical evidence is available to support this hypothesis outside of the detection of WNV and WNV antibodies in a variety of migratory and nonmigratory bird species sampled on both wintering and breeding grounds. ${ }^{10,17,18}$ However, in support of this hypothesis, viremic white storks (Ciconia ciconia) in Israel were identified during migration within 2 days of arrival at a stopover site. ${ }^{19}$ To evaluate the hypothesis that migratory birds are an important factor in the movement of WNV in North America, we

* Address correspondence to Robert J. Dusek, U.S. Geological Survey, National Wildlife Health Center, 6006 Schroeder Rd., Madison, WI 53711.E-mail:rdusek@usgs.gov sampled birds at stopover sites along migration corridors for evidence of current and past WNV infection.

\section{METHODS}

Birds were sampled at 14 study sites along the Atlantic flyway, from 2001 to 2003, and 7 study sites along the Mississippi flyway, from 2002 to 2003 (Figure 1). All sampling occurred between April 2 and May 26 (spring) and August 31 and October 21 (fall) to correlate with peak northward and southward migrations of passerine birds (Table 1). During spring migration field crews began sampling efforts at southern study sites and then moved northward; during fall migration field crews began sampling efforts at northern study sites then moved southward. In general, the goal at each location was a minimum of 4 days of sampling or 200 samples. The duration of the trapping varied depending on location, flyway, bird movements, weather, and timing of migration (Table 1).

Birds were captured using mist nets $(6,9$, and $12 \mathrm{~m}$ length $\times$ $2 \mathrm{~m}$ height, 4 panels, 36-38 $\mathrm{mm}$ mesh) suspended approximately $0.3 \mathrm{~m}$ from the ground to the net's maximum height. Nets were placed at suitable sites for the passive capture of passerine birds. The number of nets used depended on bird activity at each location and ranged from 4 to 25 . Processing of captured birds included species identification, determination of sex and age, banding with U.S. Geographical Survey (USGS) aluminum bands, and blood collection. ${ }^{20}$ Individual birds that were recaptured at the original site within the same sampling season were released and not sampled a second time and were not included in any recapture analysis; recaptured birds previously captured in other sampling seasons, or at other sites, were sampled.

Blood was primarily collected by jugular venipuncture from each bird using a sterile needle and syringe and the volume of the whole blood sample was recorded. In a limited number of cases blood was collected via the brachial vein. Blood sample volumes collected varied depending on the size of the bird and ranged from 0.01 to $1 \mathrm{~mL}$ but did not exceed $1 \%$ of body weight. All blood samples were immediately mixed with 0.9 mL BA-1 medium (M199 medium with Hank's salts and Tris $\mathrm{HCl}$ [with $7.5 \%$ sodium bicarbonate], $20 \%$ bovine serum albumin, 20\% fetal bovine serum, Penicillin-Streptomycin, $100 \mathrm{X}$, and Fungizone) in a labeled polystyrene centrifuge tube, allowed to sit in the shade at ambient temperature for 


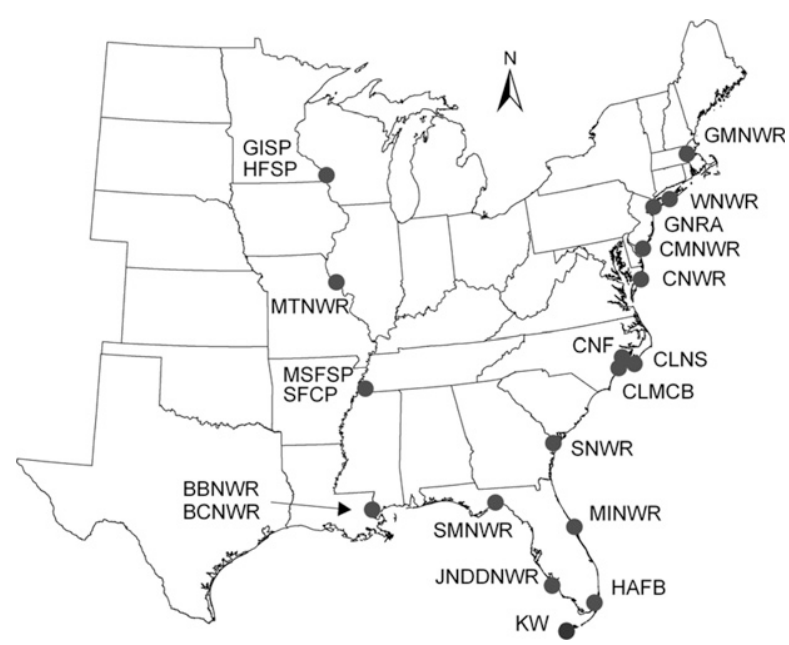

FIGURE 1. Sampling locations in the Eastern United States for both the Atlantic and Mississippi Flyways, 2001-2003. Atlantic flyway sites: GMNWR - Great Meadows National Wildlife Refuge (NWR), Massachusetts $\left(42^{\circ} 23^{\prime} \mathrm{N}, 071^{\circ} 23^{\prime} \mathrm{W}\right)$; WNWR - Wertheim NWR, New York (NY) $\left(40^{\circ} 47^{\prime} \mathrm{N}, 072^{\circ} 54^{\prime} \mathrm{W}\right)$; GNRA - Gateway National Recreation Area, NY $\left(40^{\circ} 38^{\prime} \mathrm{N}, 073^{\circ} 50^{\prime} \mathrm{W}\right)$; CMNWR - Cape May NWR, New Jersey $\left(39^{\circ} 06^{\prime} \mathrm{N}, 074^{\circ} 53^{\prime} \mathrm{W}\right)$; CNWR - Chincoteague NWR, Virginia $\left(37^{\circ} 54^{\prime} \mathrm{N}, 075^{\circ} 20^{\prime} \mathrm{W}\right)$; CNF - Croatan National Forest, North Carolina (NC) $\left(35^{\circ} 02^{\prime} \mathrm{N}, 077^{\circ} 03^{\prime} \mathrm{W}\right)$; CLNS - Cape Lookout National Seashore, NC $\left(34^{\circ} 41^{\prime} \mathrm{N}, 076^{\circ} 32^{\prime} \mathrm{W}\right)$; CLMCB - Camp Lejune Marine Corps Base, NC $\left(34^{\circ} 45^{\prime} \mathrm{N}, 077^{\circ} 30^{\prime} \mathrm{W}\right)$; SNWR Savannah NWR, South Carolina $\left(32^{\circ} 10^{\prime} \mathrm{N}, 081^{\circ} 05^{\prime} \mathrm{W}\right)$; SMNWR St. Marks NWR, Florida (FL) $\left(30^{\circ} 06^{\prime} \mathrm{N}, 084^{\circ} 10^{\prime} \mathrm{W}\right)$; MINWR - Merritt Island NWR, FL $\left(28^{\circ} 40^{\prime} \mathrm{N}, 080^{\circ} 44^{\prime} \mathrm{W}\right)$; JNDDNWR - J. N. "Ding" Darling NWR, FL $\left(26^{\circ} 27^{\prime} \mathrm{N}, 082^{\circ} 07^{\prime} \mathrm{W}\right)$; HAFB - Homestead Air Force Base, FL $\left(25^{\circ} 29^{\prime} \mathrm{N}, 080^{\circ} 24^{\prime} \mathrm{W}\right)$; KW - Key West, FL $\left(24^{\circ} 33^{\prime} \mathrm{N}\right.$, $\left.081^{\circ} 47^{\prime} \mathrm{W}\right)$. Mississippi flyway sites: GISP - Goose Island State Park (SP), Wisconsin (WI) $\left(43^{\circ} 44^{\prime} \mathrm{N}, 091^{\circ} 13^{\prime} \mathrm{W}\right)$; HFSP - Hixon Forest SP, WI $\left(43^{\circ} 49^{\prime} \mathrm{N}, 091^{\circ} 12^{\prime} \mathrm{W}\right)$; MTNWR - Mark Twain NWR, Illinois $\left(39^{\circ} 26^{\prime} \mathrm{N}, 090^{\circ} 58^{\prime} \mathrm{W}\right)$; MSFSP - Meeman-Shelby Forest SP, Tennessee (TN) $\left(35^{\circ} 21^{\prime} \mathrm{N}, 090^{\circ} 01^{\prime} \mathrm{W}\right)$; SFCP - Shelby Farms County Park, TN; BCNWR - Bogue Chitto NWR, Louisiana (LA) $\left(30^{\circ} 23^{\prime} \mathrm{N}, 089^{\circ} 45^{\prime} \mathrm{W}\right)$; BBNWR - Big Branch NWR, LA ( $\left.30^{\circ} 16^{\prime} \mathrm{N}, 089^{\circ} 56^{\prime} \mathrm{W}\right)$.

approximately $10-15$ min then held on wet ice until processing (up to $16 \mathrm{hr}$ ). At the end of each sampling day all blood samples were centrifuged for 10 minutes (at approximately $100 \times g$ ) to separate serum and BA-1 mixture from the red blood cells. The serum and BA-1 mixture was then decanted into a labeled cryovial and kept frozen using dry ice. At $~ 2$-week intervals, samples were transferred to $-80^{\circ} \mathrm{C}$ laboratory freezers until shipping on dry ice for laboratory analyses. Initial field dilution of the sample was calculated by assuming a 1:1 ratio of serum to red blood cells, so a $0.2 \mathrm{~mL}$ sample diluted with $0.9 \mathrm{~mL}$ BA-1 medium resulted in an approximate field dilution of 1:10.

All serologic testing and virus isolation was conducted at the Arbovirus Laboratories, Wadsworth Center, New York State Department of Health. Virus isolation was attempted on all collected samples. Briefly, $0.1 \mathrm{~mL}$ of each sample was inoculated on a confluent monolayer of Vero (African green monkey kidney) cells. Cells were inspected daily for up to 7 days for the presence of cytopathic effect (CPE). Cultures exhibiting CPE were harvested for isolates and identified by indirect fluorescent antibody (IFA) and reverse transcriptionpolymerase chain reaction (RT-PCR). Virus positive samples were not titrated. Nucleotide sequencing was conducted on a 700 base pair region of envelope of the viral genome of WNV isolates. ${ }^{21}$ The $\mathrm{U}$ to $\mathrm{C}$ transition at nucleotide position 1442 , resulting in a valine to alanine substitution at position 159 of the WNV E protein, indicated the virus belonged to the "WN02" clade. For serologic testing all samples were screened for anti-flavivirus antibody by indirect enzyme-linked immunosorbent assay (ELISA). ${ }^{9,22}$ Flavivirus positive ELISA samples were then tested via the plaque reduction neutralization test (PRNT) for WNV-specific and SLEV-specific neutralizing antibody and further titrated in serial 2-fold dilutions to determine the end-point titer. ${ }^{23}$ Serum samples that neutralized $\geq$ $90 \%\left(\mathrm{PRNT}_{90}\right)$ of virus were considered positive. A 4-fold or greater titer for one of the viruses indicated that particular virus as the etiologic agent for the infection. Samples that could not be differentiated by this method were deemed flavivirus positive.

Analysis of seroprevalence for all seasons combined was done using Pearson $\chi^{2}$ to test for differences in seroprevalence among the seasons. ${ }^{24}$ In addition, Cochran's Linear Trend test was used to determine whether there was an increasing (or decreasing) trend in seroprevalence between seasons. ${ }^{24}$ Further analysis of seasonal prevalence comparisons among pairs of consecutive seasons (Spring 2001 versus Fall 2001, Fall 2001 versus Spring 2002, etc.), for age and sex, and for seasonal comparisons for individual species was done by calculating the $z$ statistic and $P$ value using SYSTATs test for proportions. ${ }^{24}$ Ages that included unknown (U) in the fall and after hatchyear (AHY) in the spring were not included in the analysis by age because they were default categories for birds that could not be aged. For the comparisons of Spring 2001 versus Fall 2001 and of Fall 2001 versus Spring 2002, only Atlantic flyway data were used as sampling in the Mississippi flyway was not initiated until Spring 2002. However, data from the two flyways were combined beginning with Spring 2002 versus Fall 2002 comparisons.

\section{RESULTS}

A total of 13,403 blood samples was collected from 133 species during six sampling seasons on the Atlantic flyway $(N=$ 10,362) and four sampling seasons along the Mississippi flyway $(N=3,041)$ (Table 1$)$. All samples collected were tested for WNV and 13,365 were tested by ELISA. Samples collected varied by season and year (Atlantic flyway: $\bar{x}=1,727$, range 1,466-2,100, Mississippi flyway: $\bar{x}=760$, range 528-1,095), and by site. However, the 35 most commonly sampled species accounted for 11,166 (83\%) samples, and 67 species accounted for $95 \%$ of all samples (Table 2). Gray catbird (Dumetella carolinensis) was the most commonly sampled species representing $23.8 \%$ of all captures (Atlantic flyway: $28.5 \%$, Mississippi flyway: $7.6 \%$ ). Northern cardinal (Cardinalis cardinalis) was the second most common species sampled representing $5.7 \%$ of all captures (Atlantic flyway: 4.8\%, Mississippi flyway: $8.5 \%$ ).

In total, 12,933 individual birds were captured and sampled during this study. Four hundred seventy recaptures were obtained representing 384 ( $3 \%$ of all banded birds) individual birds; 311 birds were recaptured once, 62 birds were recaptured twice, 9 birds were recaptured 3 times, and 2 birds were recaptured 4 times. All recaptures occurred at the site of the original capture during subsequent seasons or years.

Serum samples from 19 birds were positive for infectious WNV (Table 3). Positive samples were collected only in the fall of $2002(2 / 2463,0.1 \%)$ and fall of 2003 (17/2251,0.8\%). All virus positive samples were identified as WN02 virus strain. 
TABLE 1

Beginning sampling dates and total serum samples (n) obtained for all study sites, 2001-2003

\begin{tabular}{|c|c|c|c|c|c|c|c|c|c|c|c|c|}
\hline \multirow[b]{2}{*}{ Site* } & \multicolumn{2}{|c|}{ Spring 2001} & \multicolumn{2}{|c|}{ Fall 2001} & \multicolumn{2}{|c|}{ Spring 2002} & \multicolumn{2}{|c|}{ Fall 2002} & \multicolumn{2}{|c|}{ Spring 2003} & \multicolumn{2}{|c|}{ Fall 2003} \\
\hline & Date $\dagger$ & $\mathrm{n}$ & Date & $\mathrm{n}$ & Date & $\mathrm{n}$ & Date & $\mathrm{n}$ & Date & $\mathrm{n}$ & Date & $\mathrm{n}$ \\
\hline \multicolumn{13}{|l|}{ Atlantic Flyway } \\
\hline GMNWR & $5 / 16$ & 221 & $9 / 17$ & 172 & $5 / 21$ & 227 & $9 / 1$ & 121 & $5 / 23$ & 127 & $9 / 8$ & 176 \\
\hline WNWR & $5 / 12$ & 119 & $9 / 23$ & 147 & $5 / 16$ & 223 & $9 / 6$ & 170 & $5 / 19$ & 122 & $9 / 13$ & 85 \\
\hline GNRA & $5 / 9$ & 450 & $9 / 27$ & 201 & $5 / 11$ & 339 & $9 / 11$ & 283 & $5 / 14$ & 310 & $9 / 17$ & 123 \\
\hline CMNWR & $5 / 4$ & 92 & $10 / 2$ & 197 & $5 / 7$ & 306 & $9 / 22$ & 316 & $5 / 10$ & 218 & $9 / 24$ & 224 \\
\hline CNWR & $4 / 25$ & 211 & $10 / 7$ & 416 & $5 / 1$ & 397 & $9 / 28$ & 140 & $5 / 5$ & 321 & $9 / 29$ & 234 \\
\hline $\mathrm{CNF}$ & $4 / 21$ & 80 & $10 / 12$ & 34 & & & & & & & & \\
\hline CLNS & & & $10 / 14$ & 38 & & & & & & & & \\
\hline CLMCB & $4 / 19$ & 23 & & & & & & & & & & \\
\hline SNWR & $4 / 14$ & 120 & $10 / 17$ & 275 & $4 / 26$ & 289 & $10 / 2$ & 82 & $4 / 26$ & 184 & $10 / 4$ & 263 \\
\hline SMNWR & & & $10 / 4$ & 302 & $4 / 17$ & 212 & $10 / 7$ & 351 & $4 / 18$ & 200 & $10 / 9$ & 297 \\
\hline MINWR & $4 / 9$ & 75 & & & & & & & & & & \\
\hline JNDDNWR & $4 / 2$ & 75 & & & & & & & & & & \\
\hline HAFB & & & $10 / 10$ & 52 & $4 / 12$ & 57 & & & & & & \\
\hline KW & & & $10 / 15$ & 120 & $4 / 6$ & 50 & $10 / 14$ & 209 & $4 / 12$ & 64 & $10 / 16$ & 222 \\
\hline Flyway total & & 1466 & & 1954 & & 2100 & & 1672 & & 1546 & & 1624 \\
\hline \multicolumn{13}{|l|}{ Mississippi Flyway } \\
\hline GISP & & & & & $5 / 13$ & 273 & $8 / 31$ & 90 & & & 9/17 & 114 \\
\hline HFSP & & & & & & & & & $5 / 19$ & 44 & & \\
\hline MTNWR & & & & & $5 / 6$ & 256 & $9 / 6$ & 101 & $5 / 11$ & 177 & $9 / 22$ & 83 \\
\hline MSFSP & & & & & & & $9 / 19$ & 251 & $4 / 30$ & 145 & $9 / 29$ & 88 \\
\hline SFCP & & & & & $4 / 22$ & 389 & $9 / 13$ & 49 & & & & \\
\hline BCNWR & & & & & $4 / 7$ & 110 & $9 / 30$ & 71 & $4 / 18$ & 22 & $10 / 1$ & 154 \\
\hline BBNWR & & & & & $4 / 14$ & 67 & $9 / 28$ & 229 & $4 / 19$ & 140 & $10 / 7$ & 188 \\
\hline Flyway total & & & & & & 1095 & & 791 & & 528 & & 627 \\
\hline Grand total & & 1466 & & 1954 & & 3195 & & 2463 & & 2074 & & 2251 \\
\hline
\end{tabular}

* GMNWR - Great Meadows National Wildlife Refuge (NWR), Massachusetts; WNWR - Wertheim NWR, New York (NY); GNRA - Gateway National Recreation Area, NY; CMNWR - Cape May NWR, New Jersey; CNWR - Chincoteague NWR, Virginia; CNF - Croatan National Forest, North Carolina (NC); CLNS - Cape Lookout National Seashore, NC; CLMCB - Camp Lejune Marine Corps Base, NC; SNWR - Savannah NWR, South Carolina; SMNWR -St. Marks NWR, Florida (FL); MINWR - Merritt Island NWR, FL; JNDDNWR - J. N. "Ding" Darling NWR, FL; HAFB Homestead Air Force Base; KW - Key West, FL; GISP - Goose Island State Park (SP), Wisconsin (WI); HFSP - Hixon Forest SP, WI; MTNWR - Mark Twain NWR, Illinois; MSFSP - Meeman-Shelby Forest SP, Tennessee (TN); SFCP - Shelby Farms County Park, TN; BCNWR - Bogue Chitto NWR, Louisiana (LA); BBNWR - Big Branch National Wildlife Refuge, LA.

$\dagger$ Month/first day of sampling.

Sixteen of the infected birds were aged as hatch-year (HY), 2 as AHY, and 1 as U. Viremic birds were captured as early as September 8 and as late as October 16 (Table 3). In addition to the finding of infectious WNV we also detected 19 eastern equine encephalitis virus positive birds, 5 Flander's virus positive birds, 2 Highlands $\mathbf{J}$ virus positive birds, and 9 unidentified virus positives. These findings will be detailed in a future work.

Of all sampled birds, 426 samples (representing 62 species) were positive by ELISA (Table 2). By $\mathrm{PRNT}_{90}, 254$ (representing 39 species) of the $426(60 \%)$ were positive for specific WNV-neutralizing antibody, 8 (2\%) for specific SLEV-neutralizing antibody, 30 (7\%) were undifferentiated flavivirus positive, and 129 (30\%) were negative. Four (1\%) samples lacked PRNT results and 38 were not ELISA or PRNT tested. For all samples positive by $\mathrm{PRNT}_{90}$ for specific WNV neutralizing antibody $(N=254), \mathrm{PRNT}_{90}$ titers were calculated (Table 4). Within the 426 ELISA positives, 6 individual birds were ELISA positive at two different captures. Of those 6 birds, 2 were positive for WNV antibody twice, 1 was positive for WNV antibody and was subsequently identified only as flavivirus positive, 1 was negative by $\mathrm{PRNT}_{90}$ for antibody, 1 was negative by $\mathrm{PRNT}_{90}$ for antibody and was then subsequently WNV positive, and 1 had no PRNT result, and was then subsequently negative. Seventy-three species were negative by ELISA (Table 2).

Seasonal seroprevalence rates increased from 2001 to 2003 (Pearson $\chi^{2}=301.03, \mathrm{df}=5, P<0.0005$, Cochran's Linear trend $=$ 195.27, degree of freedom [df] $=1, P<0.0005$ ) (Table 5). Significant increases in seroprevalence rates were noted between each spring sampling and subsequent fall sampling (Spring 2001-Fall 2001, $z=-3.32, P=0.0001$; Spring 2002-Fall 2002, $z=-3.51, P=0.0004$; Spring 2003-Fall 2003, $z=-7.84$, $P<0.0005)$ but not between each fall and subsequent spring sampling seasons (Fall 2001-Spring 2002, $z=0.870, P=0.384$; Fall 2002-Spring 2003, $z=-0.87, P=0.386)$. Specific WNVneutralizing antibody titers of $\geq 1: 640(N=13)$ observed in spring samples were only observed in 2003 , primarily along the Mississippi flyway, with 7 at Mark Twain NWR (northern cardinal $=3$, white-breasted nuthatch $[$ Sitta carolinensis $]=2$, prothonotary warbler $[$ Protonotaria citrea $]=1$, Baltimore oriole [Icterus galbula] =1), 3 at Louisiana sites (northern cardinal $=3$ ), and 3 in the Atlantic flyway (northern cardinal = 2, 1 each at Savannah NWR and Gateway NRA, house wren [Troglodytes aedon] = 1 Wertheim NWR). Forty-seven of the $53(89 \%)$ titers $\geq 1: 640$ that occurred in all fall samplings were detected in fall 2003, 5 occurred in fall 2002, and 1 occurred in fall 2001.

We analyzed age data for gray catbirds and sex data for northern cardinals. These analyses were limited as gray catbirds are not reliably sexed during most of the year and northern cardinals are not reliably aged during most of the year $\left(\mathrm{Pyle}^{20}\right)$. For gray catbirds captured in the fall, in all years combined, no significant difference in prevalence was noted between HY $(5.4 \%, 66 / 1230)$ and AHY $(5.5 \%, 13 / 235)$ birds $(z=0.1033$, $P=0.9178)$. In spring, in all years combined, no significant differences were detected between catbirds aged as second-year (SY) $(1.2 \%, 5 / 428)$ and after second-year (ASY) $(0.9 \%, 7 / 800)$ birds $(z=0.8173, P=0.4138)$. For all years combined, significant differences $(z=-6.67, P<0.0005)$ were noted among fall 
TABLE 2

Number of serum samples tested and results by species for the indirect enzyme-linked immunosorbent assay (ELISA) and plaque reduction neutralization test (PRNT), Atlantic and Mississippi Flyways, 2001-2003

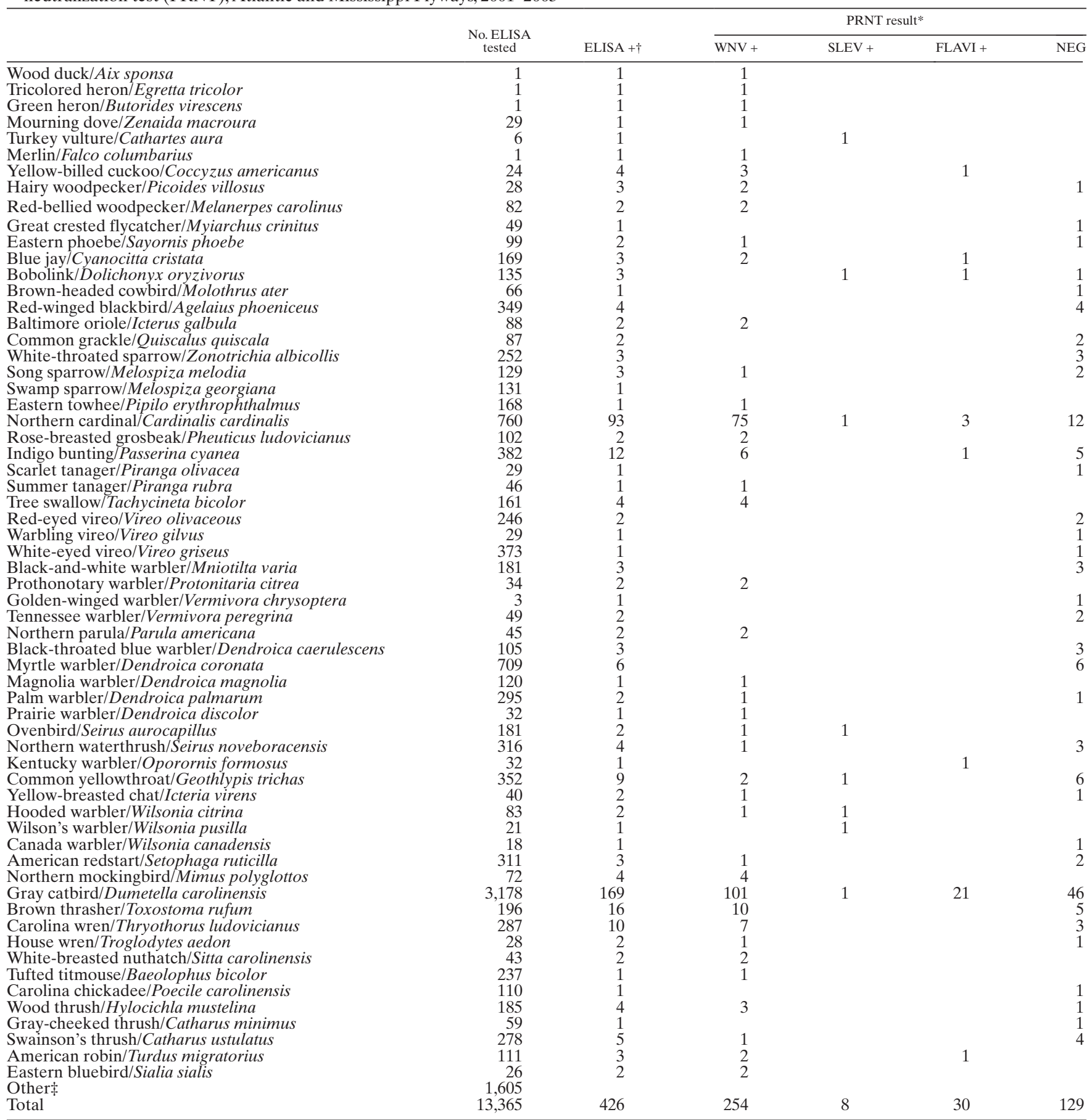

*WNV = West Nile virus antibody; SLEV = St. Louis encephalitis virus antibody; FLAVI = undifferentiated flavivirus antibody; NEG = negative, not determined to be WNV, SLEV, or FLAVI by PRNT $\dagger$ Four ELISA + samples (Swamp Sparrow [1], Northern Cardinal [2], Brown thrasher [1]) had no further testing to determine PRNT result.

†All species negative by ELISA (\# tested by ELISA). White-crowned pigeon/Columba leucocephala (1), White-winged dove/Zenaida asiatica (1), Common ground-dove/Columbina passerine (12), †All species negative by ELISA (\# tested by ELISA). White-crowned pigeon/Columba leucocephala (1), White-winged dove/Zenaida asiatica (1), Common ground-dove/Columbina passerine (12),
Sharp-shinned hawk/Accipiter striatus (15), Cooper's hawk/Accipiter cooperii (1), Northern bobwhite/Colinus virginianus (6), Eastern screech-owl/Megascops asio (2), Black-billed cuckoo/Coccyzus Sharp-shinned hawk/Accipiter striatus (15), Cooper's hawk/Accipiter cooperii (1), Northern bobwhite/Colinus virginianus (6), Eastern screech-owl/Megascops asio (2), Black-billed cuckoo/Coccyzus
erythropthalamus (2), Belted kingfisher/Ceryle alcyon (4), Downy woodpecker/Picoides pubescens (111), Yellow-bellied sapsucker/Sphyrapicus varius (14), Pileated woodpecker/Dryocopus pileatus erythropthalamus (2), Belted kingfisher/Ceryle alcyon (4), Downy woodpecker/Picoides pubescens (111), Yellow-bellied sapsucker/Sphyrapicus varius (14), Pileated woodpecker/Dryocopus pileatus
(10), Red-headed woodpecker/Melanerpes erythrocephalus (6), Northern flicker/Colaptes auratus (74), Ruby-throated hummingbird/Archilochus colubris (1), Eastern kingbird/Tyrannus tyrannus (6), (10), Red-headed woodpecker/Melanerpes erythrocephalus (6), Northern flicker/Colaptes auratus (74), Ruby-throated hummingbird/Archilochus colubris (1), Eastern kingbird/Tyrannus tyrannus (6),
Olive-sided flycatcher/Contopus cooperi (2), Eastern wood-pewee/Contopus virens( 98 ), Yellow-bellied flycatcher/Empidonax flaviventris (41), Acadian flycatcher/Empidonax virescens (29), Willow Olive-sided flycatcher/Contopus cooperi (2), Eastern wood-pewee/Contopus virens(98), Yellow-bellied flycatcher/Empidonax flaviventris (41), Acadian flycatcher/Empidonax virescens (29), Willow
flycatcher/Empidonax traillii (6), Unknown empidonax/Empidonax sp. (9), Traill's flycatcher/Empidonax traillii or alnorum (38), European starling/Sturnus vulgaris (18), Orchard oriole/Icterus spuflycatcher/Empidonax traillii (6), Unknown empidonax/Empidonax sp. (9), Traill's flycatcher/Empidonax traillii or alnorum (38), European starling/Sturnus vulgaris (18), Orchard oriole/Icterus spu-
rious (29), Boat-tailed grackle/Quiscalus major (13), House finch/Carpodacus mexicanus (21), American goldfinch/Carduelis tristis (109), Savannah sparrow/Passerculus sandwichensis (14), Whiterious (29), Boat-tailed grackle/Quiscalus major (13), House finch/Carpodacus mexicanus (21), American goldfinch/Carduelis tristis (109), Savannah sparrow/Passerculus sandwichensis (14), Whitecrowned sparrow/Zonotrichia leucophrys (12), Chipping Sparrow/Spizella passerina (10), Clay-colored sparrow/Spizella pallida (1), Field sparrow/Spizella pusilla (55), Dark-eyed junco/Junco hyemalis (5), Lincoln's sparrow/Melospiza lincolnii (35), Blue grosbeak/Guiraca caerulea (21), Painted bunting/Passerina ciris (30), Barn swallow/Hirundo rustica (1), Bank swallow/Riparia riparia (3), Northern rough-winged swallow/Stelgidopterx serripennis (3), Cedar waxwing/Bombycilla cedrorum (5), Philadelphia vireo/Vireo philadelphicus (3), Yellow-throated vireo/Vireo flavifrons (13), Blue-headed vireo/Vireo solitarius (12), Swainson's warbler/Limnothlypis swainsonii (8), Worm-eating warbler/Helmitheros vermivorus (25), Blue-winged warbler/Vermivora pinus (34), Nashville warbler/Vermivora ruficapilla (19), Orange-crowned warbler/Vermivora celata (1), Yellow warbler/Dendroica petechi (117), Chestnut-sided warbler/Dendroica pensylvanica (26), Bay-breasted warbler/Dendroica castanea (10), Blackpoll warbler/Dendroica striata (21), Blackburnian warbler/Dendroica fusca (1), Yellow-throated warbler/Dendroica dominica (8), Blackthroated green warbler/Dendroica virens (14), Pine warbler/Dendroica pinus (28), Chestnut-sided warbler/Dendroica pensylvanica (26), Louisiana waterthrush/Seirus motacilla (4), Connecticut warbler/Oporornis agilis (3), Mourning warbler/Oporornis Philadelphia (6), House sparrow/Passer domesticus (32), Marsh wren/Cistothorus palustris (1), Brown creeper/Certhia americana (9), Red-breasted nuthatch/Sitta canadensis (3), Brown-headed nuthatch/Sitta pusilla (4), Black-capped chickadee/Poecile atricapillus (196), Golden-crowned kinglet/Regulus satrapa (2), Ruby-crowned kinglet/Regulus calendula (23), Blue-gray gnatcatcher/Polioptila caerulea (5), Veery/Catharus fuscescens (70), Bicknell's thrush/Catharus bicknellii (1), Hermit thrush/Catharus guttatus (15). 
TABLE 3

West Nile virus isolations from sera of birds captured along the Atlantic and Mississippi Flyways, 2001-2003

\begin{tabular}{|c|c|c|c|c|c|}
\hline Species & Date & Sex & Age* & Site $\dagger$ & Residency: \\
\hline Indigo bunting/Passerina cyanea & 9-Sep-02 & $\mathrm{F}$ & AHY & GRNWR, IL & SR, T \\
\hline Downy woodpecker/Picoides pubescens & 9-Sep-02 & M & AHY & GRNWR, IL & $\mathrm{P}$ \\
\hline Gray catbird/Dumetella carolinensis & 8-Sep-03 & $\mathrm{U}$ & HY & GMNWR, MA & SR, T \\
\hline Tufted titmouse/Baeolophus bicolor & 8-Sep-03 & $\mathrm{U}$ & $\mathrm{HY}$ & GMNWR, MA & $\mathrm{P}$ \\
\hline Gray catbird/Dumetella carolinensis & 17-Sep-03 & $\mathrm{U}$ & HY & GNRA,NY & SR, T, WR \\
\hline Gray catbird/Dumetella carolinensis & 20-Sep-03 & $\mathrm{U}$ & HY & GNRA,NY & SR, T, WR \\
\hline Gray catbird/Dumetella carolinensis & 25-Sep-03 & $\mathrm{U}$ & HY & CMNWR, NJ & SR, T, WR \\
\hline Northern cardinal/Cardinalis cardinalis & 25-Sep-03 & $\mathrm{F}$ & HY & CMNWR, NJ & $\mathrm{P}$ \\
\hline Gray catbird/Dumetella carolinensis & 26-Sep-03 & $\mathrm{U}$ & $\mathrm{HY}$ & CMNWR, NJ & SR, T, WR \\
\hline Northern waterthrush/Seirus noveboracensis & 26-Sep-03 & $\mathrm{U}$ & HY & CMNWR, NJ & $\mathrm{T}$ \\
\hline Gray catbird/Dumetella carolinensis & 27-Sep-03 & $\mathrm{U}$ & HY & CMNWR, NJ & SR, T, WR \\
\hline American redstart/Setophaga ruticilla & 30-Sep-03 & $\mathrm{U}$ & HY & CNWR, VA & SR, T \\
\hline Brown thrasher/Toxostoma rufum & $1-$ Oct-03 & $\mathrm{U}$ & $\mathrm{U}$ & CNWR, VA & $\mathrm{SR}, \mathrm{P}, \mathrm{T}$ \\
\hline Eastern towhee/Pipilo erythrophthalmus & $1-$ Oct-03 & M & $\mathrm{HY}$ & CNWR, VA & $\mathrm{SR}, \mathrm{P}, \mathrm{T}$ \\
\hline Gray catbird/Dumetella carolinensis & $1-$ Oct-03 & $\mathrm{U}$ & HY & CNWR, VA & SR, T, WR \\
\hline Gray catbird/Dumetella carolinensis & 7-Oct-03 & $\mathrm{U}$ & HY & BBNWR, LA & WR, T \\
\hline Wood thrush/Hylocichla mustelina & $13-O c t-03$ & $\mathrm{U}$ & HY & SMNWR, FL & SR, T \\
\hline Swainson's thrush/Catharus ustulatus & 13-Oct-03 & $\mathrm{U}$ & HY & SMNWR, FL & $\mathrm{T}$ \\
\hline Indigo bunting/Passerina cyanea & 16-Oct-03 & $\mathrm{F}$ & $\mathrm{HY}$ & BCNWR, LA & $\mathrm{SR}, \mathrm{T}$ \\
\hline
\end{tabular}

$* \mathrm{HY}=$ hatch-year; $\mathrm{AHY}=$ after hatch-year; $\mathrm{U}=$ unknown.

$\dagger$ BBNWR, LA - Big Branch National Wildlife Refuge (NWR), Louisiana; BCNWR, LA - Bogue Chitto NWR, Louisiana; CMNWR, NJ - Cape May NWR, New Jersey; CNWR, VA - Chincoteague NWR, Virginia; GMNWR, MA - Great Meadows NWR, Massachusetts; GNRA, NY - Gateway National Recreation Area, New York; GRNWR, IL - Great River NWR, Illinois; SMNWR, FLSt. Marks NWR, FL.

$\ddagger \mathrm{SR}=$ summer resident; $\mathrm{T}=$ transient $\mathrm{P}=$ permanent resident; $\mathrm{WR}=$ winter resident.

and spring captures of gray catbirds. In the fall, 81 of 1,509 $(5.4 \%)$ gray catbirds were positive for WNV neutralizing antibody and in the spring 20 of $1,661(1.2 \%)$ gray catbirds were positive for WNV neutralizing antibody.

There was a significant difference in antibody prevalence among northern cardinals by season $(z=-4.11, P<0.0005)$. Across all study sites, $14.7 \%(51 / 344)$ of samples collected in the fall were positive and $5.5 \%$ (24/411) of samples collected in the spring were positive. Differences between spring and fall at Louisiana study sites were detected for all northern cardinals combined $(z=-2.732, P=0.0063) ; 26.1 \%$ (24/92) of samples were positive in the fall and $9.5 \%(7 / 74)$ of samples collected in the spring were positive. Furthermore, at the two Louisiana sites an adequate sample size of northern cardinals was available for data analysis by sex. For spring samples, no difference by sex was noted $(z=-0.55, P=0.5851) ; 7.1 \%(2 / 28)$ of males were positive and $10.9 \%(5 / 46)$ of females were positive.

\section{DISCUSSION}

The results of this study support the hypothesis that migrating birds may have played a key role in the geographic spread of WNV in the United States. We detected WNV viremia in 19 migrant and resident birds during the fall of 2002 and 2003. Although we sampled these birds during peak migratory periods, we cannot be certain as to where they obtained their infection or whether they were able to migrate once infected. Additionally, it is not known whether an individual birds virus status would influence its capture probability thereby effecting the virus prevalence we detected. ${ }^{25,26}$ Other studies of free living, wild species have yielded few detections of live virus at the time of capture. In the first year of widespread WNV activity in California, investigators were unable to detect viral activity in spring and fall migratory birds. ${ }^{6}$ In 2002, only a single virus positive bird $(1 / 264,0.4 \%)$ was detected during another study of resident wild birds during the 2002 epizootic in St. Tammany Parish, LA, even though their study sites were focused in areas of known WNV activity. ${ }^{27}$ The $0.8 \%$ detection rate of viremic birds found in the fall of 2003 in this study is a remarkable percentage considering that millions of migratory birds traverse the Atlantic and Mississippi flyways in the fall.

Detection of WNV in one northern cardinal and eight gray catbirds, in combination with the high prevalence of specific WNV neutralizing antibodies observed in these species, suggests that these two species may play a significant role in maintenance and spread of WNV. These two species have been experimentally infected with WNV and their virus profiles reported. Northern cardinals infected experimentally had viremias of $>10^{5}$ plaque forming units ( $\mathrm{pfu}$ ) for $>1$ day with dectable viremia lasting for up to 6 days post inoculation (PI). ${ }^{27}$ In gray catbirds, virus titers were of a slightly lower magnitude and were detectable for a shorter duration (up to 5 days PI), although virus titers in some individuals exceeded $10^{5}$ pfu. ${ }^{28}$ Gray catbirds and northern cardinals have also been shown to make up a high percentage of blood meals identified from mosquito species considered to be potential vectors of WNV. Gray catbird was the second most common species identified in blood meals obtained from Culex pipiens and the third most common in Culiseta melanura. ${ }^{29,30}$ Northern cardinal comprised a lower proportion of blood meals in both of these studies, but was the third most common species identified in blood meals of mosquitoes collected in Memphis and Shelby Counties, TN. ${ }^{31}$ These two bird species are common in the eastern United States and regularly occur at the ecologic interface of urban, suburban, and rural areas, and data presented from this study combined with results from these mosquito and experimental studies suggest they may be important avian hosts for the maintenance and amplification of WNV. Although both species are similar in their breeding habitats, northern cardinals are considered to be year-round residents, whereas gray catbirds are migratory, wintering in the Atlantic and Gulf Coast regions of the United States and south into the neotropics. ${ }^{32,33}$

Through experimental and modeling studies, a number of authors have concluded that migratory birds are important in the spread of WNV throughout the Western Hemisphere. 
TABLE 4

Specific West Nile virus neutralizing antibody titers obtained from avian serum samples, Atlantic and Mississippi Flyways, 2001-2003

\begin{tabular}{|c|c|c|c|c|c|c|c|c|}
\hline Species & $\mathrm{n}$ & $1: 20$ & $1: 40$ & $1: 80$ & 1:160 & $1: 320$ & 1:640 & $\geq 1: 1280$ \\
\hline \multicolumn{9}{|l|}{ Fall } \\
\hline Tricolored heron/Egretta tricolor & 1 & & & & 1 & & & \\
\hline Merlin/Falco columbarius & 1 & & & 1 & & & & \\
\hline Yellow-billed cuckoo/Coccyzus americanus & 2 & & & 1 & & & 1 & \\
\hline Hairy woodpecker/Picoides villosus & 2 & & & 1 & & & 1 & \\
\hline Red-bellied woodpecker/Melanerpes carolinus & 2 & & 2 & & & & & \\
\hline Eastern phoebe/Sayornis phoebe & 1 & & & & & 1 & & \\
\hline Blue jay/Cyanocitta cristata & 2 & & & & 1 & 1 & & \\
\hline Baltimore oriole/Icterus galbula & 1 & & & & & 1 & & \\
\hline Song sparrow/Melospiza melodia & 1 & & & & & & 1 & \\
\hline Northern cardinal/Cardinalis cardinalis & 51 & 1 & & 5 & 6 & 15 & 24 & \\
\hline Rose-breasted grosbeak/Pheuticus ludovicianus & 2 & & & & & & 2 & \\
\hline Indigo bunting/Passerina cyanea & 6 & & & 1 & & 3 & 1 & 1 \\
\hline Summer tanager/Piranga rubra & 1 & & & 1 & & & & \\
\hline Tree swallow/Tachycineta bicolor & 4 & & & & 2 & & 1 & 1 \\
\hline Northern parula/Parula americana & 2 & & & & & & 1 & 1 \\
\hline Magnolia warbler/Dendroica magnolia & 1 & & 1 & & & & & \\
\hline Palm warbler/Dendroica palmarum & 1 & 1 & & & & & & \\
\hline Prairie warbler/Dendroica discolor & 1 & & 1 & & & & & \\
\hline Ovenbird/Seirus aurocapillus & 1 & & & & 1 & & & \\
\hline Common yellowthroat/Geothlypis trichas & 2 & & & & & & 1 & 1 \\
\hline Yellow-breasted chat/Icteria virens & 1 & & & & & 1 & & \\
\hline Hooded warbler/Wilsonia citrine & 1 & & & & & & & 1 \\
\hline American redstart/Setophaga ruticilla & 1 & & 1 & & & & & \\
\hline Northern mockingbird/Mimus polyglottos & 2 & & & 2 & & & & \\
\hline Gray catbird/Dumetella carolinensis & 81 & 2 & 10 & 20 & 26 & 16 & 7 & \\
\hline Brown thrasher/Toxostoma rufum & 10 & & 1 & 2 & 2 & 4 & 1 & \\
\hline Carolina wren/Thryothorus ludovicianus & 7 & & & 1 & 1 & 2 & 3 & \\
\hline Tufted titmouse/Baeolophus bicolor & 1 & & & & & & 1 & \\
\hline Wood thrush/Hylocichla mustelina & 3 & & & 3 & & & & \\
\hline Swainson's thrush/Catharus ustulatus & 1 & & & 1 & & & & \\
\hline American robin/Turdus migratorius & 2 & & & 1 & & & 1 & \\
\hline Eastern bluebird/Sialia sialis & 2 & & & & & & 2 & \\
\hline \multicolumn{9}{|l|}{ Spring } \\
\hline Wood duck/Aix sponsa & 1 & & & 1 & & & & \\
\hline Green heron/Butorides virescens & 1 & & & 1 & & & & \\
\hline Mourning dove/Zenaida macroura & 1 & & & 1 & & & & \\
\hline Yellow-billed cuckoo/Coccyzus americanus & 1 & & & & 1 & & & \\
\hline Baltimore oriole/Icterus galbula & 1 & & & & & & 1 & \\
\hline Northern cardinal/Cardinalis cardinalis & 24 & & 3 & 4 & 4 & 5 & 6 & 2 \\
\hline Prothonotary warbler/Protonitaria citrea & 2 & & & 1 & & & 1 & \\
\hline Northern waterthrush/Seirus noveboracensis & 1 & & & & 1 & & & \\
\hline Northern mockingbird/Mimus polyglottos & 2 & & 1 & & 1 & & & \\
\hline Gray catbird/Dumetella carolinensis & 20 & 4 & 6 & 7 & 2 & 1 & & \\
\hline House wren/Troglodytes aedon & 1 & & & & & & 1 & \\
\hline White-breasted nuthatch/Sitta carolinensis & 2 & & & & & & 1 & 1 \\
\hline
\end{tabular}

When Swainson's thrushes (Catharus ustulatus) and gray catbirds were experimentally infected with WNV, no difference in migratory restlessness was detected between infected and control groups, leaving the authors to conclude that both of these species could potentially disperse WNV along their migratory route. ${ }^{28}$ In one theoretic model, the investigators concluded that migratory birds were the long-distance transport agents for WNV, with gray catbird being one of the 41 migratory bird species included in the model. ${ }^{14}$ We detected viremic migratory birds at migratory passerine stopover sites along the east and gulf coasts during peak periods of fall passerine migration. Although we were unable to detect movement of these viremic birds during this study, our data provide additional evidence that migratory birds may play an important role in the long-distance movement of WNV.

During this study, a low seroprevalence of antibody to WNV was detected, but a significant increasing trend was also observed as reported in other similar studies. ${ }^{34}$ In spring 2003 we detected 13 antibody titers $\geq 1: 640$, not previously seen in spring 2001 or 2002 samples, compared with only five antibody titers $\geq 1: 640$ in fall of 2002. Increased transmission of WNV over winter may have led to an increase in circulating virus in northbound migrants and therefore earlier and more widespread transmission at northern latitudes in 2003, which eventually lead to the increase in seroprevalence and viremic birds we detected in the fall of 2003. This scenario generally follows WNV transmission models previously developed. ${ }^{14}$ In January 2004, WNV was detected in a dead northern cardinal in Louisiana and 10 other passerine birds in eastern Texas tested between November 2003 and March 2004, indicating that there is year-round transmission of WNV along the gulf coast of the United States. ${ }^{35}$

Overall, annual seroprevalence rates by year in this study are similar to what has been detected in other studies with more limited geographic coverage. On Staten Island, New York, after an observed outbreak in 2000, 23\% of resident birds and no migrant birds had detectable anti-WNV antibody. ${ }^{17}$ In Illinois, overall prevalence of anti-WNV antibody 
TABLE 5

Prevalence of specific West Nile virus neutralizing antibody, for all species combined, at Atlantic and Mississippi Flyway study sites, 2001-2003

\begin{tabular}{|c|c|c|c|c|c|c|}
\hline Site* & $\underset{(\%)}{\text { Spring } 01}$ & $\begin{array}{c}\text { Fall } 01 \\
(\%)\end{array}$ & $\underset{(\%)}{\text { Spring } 02}$ & $\begin{array}{c}\text { Fall } 02 \\
(\%)\end{array}$ & $\underset{(\%)}{\text { Spring }} 03$ & $\begin{array}{c}\text { Fall } 03 \\
(\%)\end{array}$ \\
\hline \multicolumn{7}{|l|}{ Atlantic Flyway } \\
\hline GMNWR & 0.0 & 0.6 & 0.4 & 0.8 & 0.0 & 1.2 \\
\hline WNWR & 0.0 & 2.7 & 3.6 & 1.2 & 1.6 & 4.7 \\
\hline GNRA & 0.2 & 2.0 & 0.6 & 1.1 & 1.9 & 0.8 \\
\hline CMNWR & 0.0 & 1.0 & 0.7 & 0.0 & 0.9 & 12.9 \\
\hline CNWR & 0.0 & 0.0 & 0.3 & 0.0 & 0.9 & 6.2 \\
\hline $\mathrm{CNF}$ & 0.0 & 0.0 & & & & \\
\hline CLNS & & 0.0 & & & & \\
\hline CLMCB & 0.0 & & & & & \\
\hline SNWR & 0.0 & 0.7 & 0.0 & 0.0 & 1.6 & 7.3 \\
\hline SMNWR & & 1.7 & 0.0 & 0.0 & 0.0 & 7.2 \\
\hline MINWR & 0.0 & & & & & \\
\hline JNDDNWR & 1.3 & & & & & \\
\hline HAFB & & 0.0 & 0.0 & & & \\
\hline KW & & 1.7 & 0.0 & 0.0 & 0.0 & 6.0 \\
\hline Flyway total & 0.1 & 1.0 & 0.8 & 1.0 & 1.0 & 6.4 \\
\hline \multicolumn{7}{|l|}{ Mississippi Flyway } \\
\hline GISP & & & 0.0 & 0.0 & & 0.9 \\
\hline HFSP & & & & & 0.0 & \\
\hline MTNWR & & & 0.4 & 4.0 & 6.8 & 3.6 \\
\hline MSFSP & & & & 2.0 & 0.0 & 3.4 \\
\hline SFCP & & & 0.0 & 18.4 & & \\
\hline BCNWR & & & 0.0 & 1.4 & 0.0 & 11.1 \\
\hline BBNWR & & & 0.0 & 0.0 & 6.4 & 8.6 \\
\hline Flyway total & & & 0.1 & 2.4 & 4.0 & 6.4 \\
\hline Grand total & 0.1 & 1.0 & 0.6 & 1.4 & 1.8 & 6.4 \\
\hline
\end{tabular}

*GMNWR - Great Meadows National Wildlife Refuge (NWR), Massachusetts; WNWR Wertheim NWR, New York (NY); GNRA - Gateway National Recreation Area, NY; CMNWR - Cape May NWR, New Jersey; CNWR - Chincoteague NWR, Virginia; CNF Croatan National Forest, North Carolina (NC); CLNS - Cape Lookout National Seashore, NC; CLMCB - Camp Lejune Marine Corps Base, NC; SNWR - Savannah NWR, South Carolina; SMNWR -St. Marks NWR, Florida (FL); MINWR - Merritt Island NWR, FL; JNDDNWR J. N. "Ding" Darling NWR, FL; HAFB - Homestead Air Force Base, FL; KW - Key West, FL; GISP - Goose Island State Park (SP), Wisconsin (WI); HFSP - Hixon Forest SP, WI; MTNWR - Mark Twain NWR, Illinois; MSFSP - Meeman-Shelby Forest SP, Tennessee (TN); SFCP - Shelby Farms County Park, TN; BCNWR - Bogue Chitto NWR, Louisiana (LA); BBNWR - Big Branch National Wildlife Refuge, LA.

was $4.1 \%$ in wild birds in 2002, the first year of widespread WNV activity in that state. ${ }^{36}$ Seroprevalence rates of $25 \%$ and $24 \%$ were reported for resident wild birds in urban locations in St. Tammany Parish, LA in August and October 2002, respectively. ${ }^{27}$ In this study, birds were sampled on National Wildlife Refuges, also located within St. Tammany Parish, in late September and early October of 2002, but we found seroprevalence of only $1-2.1 \%$ among a similar group of resident wild birds as Komar and others ${ }^{27}$ sampled. The difference between these rates is likely because of sampling locations. Komar and others ${ }^{27}$ sampled at locations that were known areas where WNV positive human, horse, dead bird and/or mosquito samples were collected, although we selected sites with no known WNV activity but were likely to have higher migratory bird use. In this study, seroprevalence rates in 2003, again among a similar group of species that Komar and others sampled in 2002 and at the same study sites we initially sampled in 2002, increased to $22 \%$. This increase in seroprevalence and the detection of WNV viremias in two birds during that fall at these same locations, suggest increased rates of WNV transmission in the parish after the initial year of widespread activity in 2002 in Louisiana.

Of all the species in this study that had detectable specific WNV-neutralizing antibody, northern cardinals and gray catbirds were the most commonly found with WNV antibody, but these were two of the most commonly sampled species in this study. Other studies have also detected relatively high rates of anti-WNV antibody in these two species..$^{17,34,36}$ Because of the large sample sizes of these species and the frequency in which anti-WNV antibody was detected among them, we analyzed gray catbird data by age and northern cardinal data by sex. In contrast to reports from an Ohio study, we detected no sex bias in seroprevalence rates in northern cardinals. ${ }^{37}$ The only difference detected for these species was a significant increase in prevalence for birds sampled in the fall over that of spring captured birds as was the trend observed throughout this study.

The goal of the current study was to determine the role migrating birds played in the geographic spread of WNV. We detected a low prevalence of viremia among birds sampled at migratory stopover sites during peak periods of migration, however, in the context of millions of birds that migrate each year this low prevalence could still be significant. Results of this study also suggest that gray catbirds and northern cardinals may play a significant role in the transmission ecology of WNV as maintenance or amplification hosts and these species should be further examined to determine the extent of this role.

Received February 25, 2009. Accepted for publication August 18, 2009.

Acknowledgments: We thank the many people who helped with this project. R. Lord, T. Barnes, K. Cutrera, D. Berndt, K. Morris, A. Hammond, L. DeGroot, H. Gutzman, K. Stumpf, D. Licata, K. Wright, N. Ramsey, K. Cranker, D. Roberts, J. Floyd, M. Daniels, J. Peterla, and E. Tillman provided assistance with field sampling. We are also grateful to J. Maffei for his assistance with cell culture, and the Wadsworth Center for tissue culture. We thank all the institutions that allowed us access to their properties, including Great Meadows National Wildlife Refuge (NWR), Wertheim NWR, Gateway National Recreation Area, Cape May NWR, Chincoteague NWR, Croatan National Forest, Camp Lejuene Marine Corps Base, Cape Lookout National Seashore, Savannah NWR, St. Marks NWR, The City of Key West, Homestead Air Force Base, J. N. "Ding" Darling NWR, Merritt Island NWR, Goose Island State Park, Hixon Forest State Park, Great River NWR, Shelby Farms County Park, MeemanShelby Forest State Park, Southeast Louisiana NWR. We thank F. Ford, C. Snell, M. Rikard, R. Webb, H. Marrow, J. Reinman, B. Luebke, H. Shclegel, E. Ailes, T. Penn, C. Parker, L. Lacy, C. Chambers, J. Nissen, M. Kofman, M. Maghini, D. Reipi, G. Frame, S. Smith, S. Koch, S. Hanna, and L. Hillmann for logistical support.

Disclaimer: None of the authors have any financial interest or conflict of interest with this article. Any use of trade, product, or firm names is for descriptive purposes only and does not imply endorsement by the U.S. government.

Authors' addresses: Robert J. Dusek, U.S. Geological Survey, National Wildlife Health Center, 6006 Schroeder Rd., Madison, WI 53711, Tel: 608-270-2400, Fax: 608-270-2415, E-mail: rdusek@usgs.gov. Robert G. McLean, U.S. Geological Survey, National Wildlife Health Center, 6006 Schroeder Rd., Madison, WI 53711; current address: U.S. Department of Agriculture, National Wildlife Research Center, 4101 Laporte Ave., Fort Collins, CO 80521, Tel: 970-266-6066, Fax: 970-266-6089, E-mail: Robert.G.McLean@aphis.usda.gov. Laura D. Kramer and Alan P. Dupuis II, New York State Department of Health, 5668 State Farm Rd., Slingerlands, NY 12159, Tel: 518-869-4524, Fax: 518-869-4530, E-mails: 1dk02@health.state.ny.us and apd05@health.state.ny.us. Sonya R. Ubico, U.S. Geological Survey, National Wildlife Health Center, 6006 Schroeder Rd., Madison, WI 53711; current address: 407 Idalia Drive, Fort Collins, CO 80521. Gregory D. Ebel, New York State Department of Health, 5668 State Farm Rd., Slingerlands, NY 12159; current address: University of New Mexico School of Medicine, 915 Camino de Salud, Albuquerque, NM 87131, Tel: 505-272-3163, Fax: 505-272-5186, E-mail: gebel@salud.unm.edu. Stephen C. Guptill, U.S. Geological Survey, Eastern Region Geography, 521 National Center, Reston, VA 20192; current address: Geographic Information Science and Spatial Epidemiology, 3431 Lyrac Street, Oakton, VA 22124, Tel: 703-881-2495,E-mail: sguptill@guptillgeoscience.com. 
Reprint requests: Robert J. Dusek, U.S. Geological Survey, National Wildlife Health Center, 6006 Schroeder Rd., Madison, Wisconsin, 53711, Tel: 608-270-2400, Fax: 608-270-2415, E-mail: rdusek@usgs.gov.

\section{REFERENCES}

1. Germendia AE, Van Kruiningen HJ, French RA, 2001. The West Nile virus: its recent emergence in North America. Microbes Infect 3: 223-229.

2. Marfin AA, Petersen LR, Eidson M, Miller J, Hadler J, Farello C, Werner B, Campbell GL, Layton M, Smith P, Bresnitz E, Cartter M, Scaletta J, Obiri G, Bunning M, Craven RC, Roehrig JT, Julian KG, Hinten SR, Gubler DJ, ArboNET Cooperative Surveillance Group, 2001. Widespread West Nile virus activity, eastern United States, 2000. Emerg Infect Dis 7: 730-735.

3. Blackmore CGM, Stark LM, Jeter WC, Oliveri RL, Brooks RG, Conti LA, Wiersma ST, 2003. Surveillance results from the first West Nile virus transmission season in Florida, 2001. Am J Trop Med Hyg 69: 141-150.

4. McLean RG, 2002. West Nile virus. A threat to North American avian species. Transaction 67th North American Wildlife Natural Resource Conference 2002, 62-74.

5. O'Leary DR, Marfin AA, Montgomery SP, Kipp AM, Lehman JA, Biggerstaff BJ, Elko VL, Collins PD, Jones JE, Campbell GL, 2004. The epidemic of West Nile virus in the United States, 2002. Vector Borne Zoonotic Dis 4: 61-70.

6. Reisen W, Lothrop H, Chiles R, Madon M, Cossen C, Woods L, Husted S, Kramer V, Edman J, 2004. West Nile virus in California. Emerg Infect Dis 10: 1369-1378.

7. Hayes N, 2004. Summary of West Nile virus activity, United States 2003. Fifth National Conference on West Nile Virus in the United States. Centers for Disease Control and Prevention. Available at: www.cdc.gov/ncidod/dvbid/westnile/conf/index .htm. Accessed May 29, 2008.

8. Drebot MA, Lindsay LR, Barker IK, Buck PA, Fearon M, Hunter F, Sockett P, Artsob H, 2003. West Nile virus surveillance and diagnostics: a Canadian perspective. Can J Infect Dis 14: 105-114.

9. Dupuis AP II, Marra PP, Kramer LD, 2003. Serologic evidence of West Nile virus transmission, Jamaica, West Indies. Emerg Infect Dis 9: 860-863.

10. Farfan-Ale JA, Blitvich BJ, Lorono-Pino MA, Marlenee NL, Rosado-Paredes EP, Garcia-Rejon JE, Flores-Flores LF, Chulim-Perera L, Lopez-Uribe M, Perez-Mendoza G, SanchezHerrera I, Santamaria W, Moo-Huchim J, Gubler DJ, Cropp BC, Calisher CH, Beaty BJ, 2004. Longitudinal studies of West Nile virus infection in avians, Yucatan State, Mexico. Vector Borne Zoonotic Dis 4: 3-14.

11. Komar N, 2003. West Nile virus: epidemiology and ecology in North America. Adv Virus Res 61: 185-234.

12. McLean RG, Ubico SR, Docherty DE, Hansen WR, Sileo L, McNamara TS, 2001. West Nile virus transmission and ecology in birds. Ann N Y Acad Sci 951: 54-57.

13. LaDeau SA, Kilpatrick AM, Marra PP, 2007. West Nile virus emergence and large-scale declines of North American bird populations. Nature 447: 710-714.

14. Peterson AT, Vieglais DA, Andreasen JK, 2003. Migratory birds modeled as critical transport agents for West Nile virus in North America. Vector Borne Zoonotic Dis 3: 27-37.

15. Reed KD, Meece JK, Henkel JS, Shukla SK, 2003. Birds, migration, and emerging zoonoses: West Nile virus, lyme disease, influenza A, and enteropathogens. Clin Med Res 1: 5-12.

16. Rappole JH, Derrickson SR, Hubalek Z, 2000. Migratory birds and spread of West Nile virus in the western hemisphere. Emerg Infect Dis 6: 319-328.

17. Komar N, Burns J, Dean C, Panella NA, Dusza S, Cherry B, 2001. Serologic evidence for West Nile virus infection in birds in Staten Island, New York, after an outbreak in 2000. Vector Borne Zoonotic Dis 1: 191-196.

18. Komar O, Robbins MB, Klenk K, Blitvich BJ, Marlenee NL, Burkhalter KL, Gubler DJ, Gonzalvez G, Pena CJ, Peterson AT, Komar N, 2003. West Nile virus transmission in resident birds, Dominican Republic. Emerg Infect Dis 9: 1299-1302.
19. Malkinson M, Banet C, Weisman Y, Pokamunski S, King R, Drouet M-T, Deubel V, 2002. Introduction of West Nile virus in the middle east by migrating white storks. Emerg Infect Dis 8: 392-397.

20. Pyle P, 1997. Identification Guide to North American Birds. Part I. Bolinas, CA: Slate Creek Press.

21. Ebel GD, Carricaburu J, Young D, Bernard KA, Kramer LD, 2004. Genetic and phenotypic variation of West Nile virus in New York, 2000-2003. Am J Trop Med Hyg 71: 493-500.

22. Ebel GD, Dupuis AP, Nicholas D, Young D, Maffei J, Kramer LD, 2002. Detection by enzyme-linked immunosorbent assay of antibodies to West Nile virus in birds. Emerg Infect Dis 8: 979-982.

23. Lindsey HS, Calisher CH, Matthews JH, 1976. Serum dilution neutralization test for California group virus identification and serology. J Clin Microbiol 4: 503-510.

24. Systat, 2007. SYSTAT 12 Statistics - I. San Jose, CA: SYSTAT Software, Inc.

25. Jennelle CS, Cooch EG, Conroy MJ, Senar JC, 2007. State-specific detection probabilities and disease prevalence. Ecol Appl 17: 154-167.

26. Senar JC, Conroy MJ, 2004. Multi-state analysis of the impacts of avian pox on a population of Serins (Serinus serinus): the importance of estimating recapture rates. Anim Biodivers Conserv 27: 133-146.

27. Komar N, Panella NA, Langevin SA, Brault AC, Amador M, Edwards E, Owen JC, 2005. Avian hosts for West Nile virus in St. Tammany Parish, Louisiana, 2002. Am J Trop Med Hyg 73: 1031-1037.

28. Owen J, Moore F, Panella N, Edwards E, Bru R, Hughes M, Komar N, 2006. Migrating birds as dispersal vehicles for West Nile virus. EcoHealth 3: 79-85.

29. Molaei G, Andreadis TG, Armstrong PM, Anderson JF, Vossbrinck CR, 2006. Host feeding patterns of Culex mosquitoes and West Nile virus transmission, northeastern United States. Emerg Infect Dis 12: 468-474.

30. Molaei G, Andreadis TG, 2006. Identification of avian- and mammalian-derived blood meals in Aedes vexans and Culiseta melanura (Diptera: Culicidae) and its implication for West Nile virus transmission in Connecticut, USA. J Med Entomol 43: 1088-1093.

31. Savage HM, Aggarwal D, Apperson CS, Katholi CR, Gordon E, Hassan HK, Anderson M, Charnetzky D, McMillen L, Unnasch EA, Unnasch TR, 2007. Host choice and West Nile virus infection rates in blood-fed mosquitoes, including members of the Culex pipiens complex, from Memphis and Shelby County, Tennessee, 2002-2003. Vector Borne Zoonotic Dis 7: 365-386.

32. Halkin SL, Linville SU, 1999. Northern cardinal (Cardinalis cardinalis). Poole A, ed. The Birds of North America. Ithaca, NY: Cornell Lab of Ornithology; Retrieved from the Birds of North America Online. Available at: http://bna.birds.cornell.edu/bna/ species/440. Accessed November 24, 2008.

33. Cimprich DA, Moore FR, 1995. Gray catbird (Dumetella carolinensis). Poole A, ed. The Birds of North America. Ithaca, NY: Cornell Lab of Ornithology; Retrieved from the Birds of North America Online. Available at: http://bna.birds.cornell.edu/bna/ species/167. Accessed November 24, 2008.

34. Gibbs SEJ, Allison AB, Yabsley MJ, Mead DG, Wilcox BR, Stallknecht DE, 2006. West Nile virus antibodies in avian species of Georgia, USA: 2000-2004. Vector Borne Zoonotic Dis 6: $57-72$.

35. Tesh RB, Parsons R, Siirin M, Randle Y, Sargent C, Guzman H, Wuithiranyagool T, Higgs S, Vanlandingham DL, Bala A, Haas K, Zerinque B, 2004. Year-round West Nile virus activity, Gulf Coast Region, Texas and Louisiana. Emerg Infect Dis 10: 1649-1652.

36. Ringia AM, Blitvich BJ, Koo H-Y, Van de Wyngaerde M, Brawn JD, Novak RJ, 2004. Antibody prevalence of West Nile virus in birds, Illinois, 2002. Emerg Infect Dis 10: 1120-1124.

37. Marshall JS, Zuwerink DA, Restifo RA, Grubb TC Jr, 2006. West Nile virus in the permanent-resident bird community of a fragmented Ohio landscape. Ornithol Monogr 60: 79-85. 